\title{
PROPAGAÇÃO VEGETATIVA IN VITRO DE CULTIVARES DE MACIEIRA (1)
}

\author{
WILSON BARBOSA $\left({ }^{2,4}\right)$, FERNANDO ANTONIO CAMPO DALL'ORTO $(2,4)$, \\ MÁRIO OJMA $\left({ }^{2}\right)$, SÔNIA APARECIDA FERRAZ DE CAMPOS $\left(^{3}\right)$ \\ e ANTONIO FERNANDO CAETANO TOMBOLATO $(2,4)$
}

\section{RESUMO}

$O$ presente trabalho é resultado de uma série de experimentos desenvolvidos na Seção de Fruticultura de Clima Temperado do IAC, no sentido de adaptar e aperfeiçoar a técnica da micropropagação da macieira. Foram pesquisadas, para os cultivares Rainha e Gala e para as seleçōes IAC 1381-22, IAC 3881-8 e IAC 4881-11, as principais exigências hormonais, nas várias fases do crescimento e da proliferação dos meristemas, para a indução de raiz, efetivo enraizamento e desenvolvimento apical. Na primeira fase, os meristemas cresceram em meio de cultura constituído da solução salina de Murashige \& Skoog com adição de tiamina 1,0mg/litro, ácido nicotíni$\mathrm{co}, 0,25 \mathrm{mg} /$ litro, inositol $100 \mathrm{mg} /$ litro, ágar $6,5 \mathrm{~g} /$ litro, sacarose $30 \mathrm{~g} /$ litro e 6-benzilaminopurina (BAP) a 0, 2,5, 5,0, 7,5 e 15,0 $\mu \mathrm{M}$. Na segunda fase, os propágulos foram repicados e colocados em um meio indutor de raiz, com a mesma constituição básica inicial, por cinco dias em ambiente escuro, substituindo-se, porém, a citocinina pela auxina ácido indolbutírico (AIB) a 0, 1,0, $2,0,4,0$ e $8,0 \mu \mathrm{M}$. Na terceira e última fase, os propágulos foram transferidos em meio para o crescimento das raízes, mantendo-se ainda a mesma constituição básica, reduzindo-se, porém, a sacarose a $10 \mathrm{~g}$ /litro e excluindo-se totalmente os fitormônios. Os dados mostraram claramente, para os materiais utilizados, que os melhores índices de crescimento, proliferação e de enraizamento dos explantes, foram obtidos na faixa de 7,5 $\mu \mathrm{M}$ de BAP e 2,0 $\mu \mathrm{M}$ de AIB respectivamente. Os propágulos enraizados, apos retirados das condiçōes in vitro, foram plantados em vermiculita expandida, e aclimatizados em miniestufa por quinze dias, sendo finalmente transplantados para vasos com terra e mantidos em casa de vegetação.

Termos de indexação: macieira, Malus spp.; meristema; cultura; enraizamento in vitro; explante; propágulo; BAP e AIB.

(1) Trabalho de pesquisa ligado ao projeto: "Melhoramento genético da macieira - Malus spp." Convênio: SAA-IAC-EMBRAPA. Recebido para publicação em 29 de agosto de 1985.

(2) Seção de Fruticultura de Clima Temperado, Divisão de Horticultura, Instituto Agronômico (IAC), Caixa Postal 28, 13001 Campinas (SP).

(3) Atualmente, no Laboratớrio Central da Coopersucar, 13400 Piracicaba (SP).

(4) Com bolsa de suplementação do CNPq. 


\section{INTRODUÇÃO}

A propagação vegetativa da macieira é feita habitualmente pela enxertia dos cultivares-copa em porta-enxertos clonais obtidos pelo processo de amontoa-de-cepa. Dentre os cultivares porta-enxertos utilizados nas condiçōes brasileiras, destacam-se, em São Paulo, 'Doucin' e 'MM 106', e em Santa Catarina e Rio Grande do Sul, 'MM 106”, 'EM 26, 'MM 111' e 'EM 25', dependendo do porte que se pretenda conferir à copa (EMPRESA BRASILEIRA DE ASSISTÉNCIA TÉCNICA E EXTENSÄO RURAL/EMPRESA BRASILEIRA DE PESQUISA AGROPECUÁRIA, 1984). Porta-enxertos de sementes podem ser inclusive empregados quando se deseja obter o máximo vigor (CAMPO DALL'ORTO et alii, 1978).

Por esse método tradicional de propagação, a quantidade de mudas obtidas sofre restriçöes conforme a capacidade do viveirista na formação dos porta-enxertos e posterior realização da enxertia. $O$ processo demanda muito tempo, mão-de-obra e considerável espaço físico, além de possibilitar eventualmente a propagação de materiais com problemas fitossanitários.

Outras técnicas recentemente em desenvolvimento podem propiciar a obtenção de maiores quantidades de materiais de propagação da macieira, em tempo abreviado, e de melhor qualidade fitossanitária. Nesse sentido, muitos pesquisadores têm experimentado com relativo sucesso sua propagação através do cultivo in vitro ou micropropagação (ABBOT \& WHITELEY, 1976; JONES \& HATFIELD, 1976; VAZ \& NEGUEROLES, 1979; ZIMMERMAN \& BROOME, 1981; JAMES \& THURBON, 1981; LANE \& MCDOUGALD, 1982; BARBOSA et alii, 1983; SIMMONDS, 1983, e WELANDER, 1983).

Essa técnica consiste no cultivo asséptico de ápices caulinares em meios nutritivos, contendo concentraçōes apropriadas de auxinas e citocininas para a indução de crescimento, proliferação e enraizamento. Algumas dificuldades surgidas nos primeiros ensaios da cultura in vitro da macieira, sobretudo na fase do enraizamento, foram solucionadas com a utilização do ácido indolbutfrico (AIB) e do floroglucionol (PG), associados ou utilizados isoladamente por curtos períodos (JONES \& HATFIELD, 1976; VAZ \& NEGUEROLES, 1979; JAMES \& THURBON, 1981: SIMMONDS, 1983, e WELANDER, 1983).

A cultura de tecidos poderá contribuir decisivamente ao próprio melhoramento genético da macieira. Constitui valiosa técnica auxiliar de trabalho, podendo propiciar a obtenção de plantas haplóides e poliplóides, híbridos intergenéricos e interespecíficos, a indução, o cultivo e a seleção de explantes mutantes na resistência às doenças, alêm de inúmeras outras aplicações de ordem técnico-cultural.

Poucos trabalhos relatam o comportamento fitotécnico das macieiras obtidas pela micropropagação direta e cultivada sobre suas próprias raizes, sem o uso de porta-enxertos. Experimentos envolvendo sua propagação direta, pela 
estaquia de ramos de plantas adultas, foram realizados pela Seção de Fruticultura de Clima Temperado $\left({ }^{5}\right)$, sem, porém, ter chegado a resultados práticos, devido à extrema dificuldade dos cultivares utilizados de enraizar em terra pelos processos convencionais.

O presente trabalho demonstra a viabilidade da micropropagação direta de cultivares de macieira, utilizados em pesquisas na Seção de Fruticultura de Clima Temperado. Os resultados servem de subsídios para a adoção da metodologia da cultura in vitro a outras pesquisas visando aplicações comerciais por viveiristas.

\section{MATERIAL E MÉTODOS}

\section{Cultivares utilizados}

Utilizaram-se os seguintes materiais de macieira, coletados dos lotes experimentais da Seção de Fruticultura 'de Clima Temperado: 'Rainha' (IAC 8-31), 'Gala', IAC 1381-22, IAC 3881-8 e IAC 4881-11.

'Rainha' (IAC 8-31) (RIGITANO et alii, 1984), cultivar lançado pelo Instituto Agronômico em 1975, mercê da superior qualidade das frutas e da boa adaptação às condições de inverno brando, constitui hoje a macieira de maior expansão nos pomares comerciais paulistas. 'Gala' (RIBEIRO et alii, 1982), originário da Nova Zelândia, considerado uma das melhores maçãs da atualidade, tem encontrado, no Brasil, boa adaptaçãó nas regiões de maior altitude dos estados sulinos. Os três restantes representam híbridos $F 1$ do programa de melhoramento da macieira, em fase de propagação inicial: IAC 1381-22 ('Golden Delicious' x 'Anna'); IAC 3881-8 ('Rainha' x 'Michal') e IAC 4881-11 ('Brasil', polinização natural).

\section{Preparação dos materiais}

Objetivando-se evitar contaminações dos meristemas em cultura, os ramos coletados do pomar foram tratados, por imersão, com produtos fungicidas e bactericidas, alguns de largo espectro. Os tratamentos não se mostraram adequados, uma vez que os patógenos contidos no interior da gema não foram atingidos pelos produtos. Verificou-se também que, à medida que os foliculos eram destacados das gemas, a água resultante das lavagens dos produtos ficava retida e penetrava lentamente, carregando os esporos, que, no ato da excisão do meristema, aderiam à superficie, ocasionando a sua contaminação e a do próprio meio de cultura, tornando posteriomente impossivel a recuperação do explante.

O procedimento se tornou mais prático e eficiente quando se fez uma breve esterilização dos ramos vegetativos jovens, contendo gemas laterais dormentes, limpando-os superficialmente com algodão levemente umedecido em ál-

(5) CAMPINAS. Instituto Agronómico. Relatório Anual da Seçâo de Fruticultura de Clima Temperado. Campinas, 1967. (Não publicado) 
cool $96^{\circ} \mathrm{GL}$. Os ramos foram cortados em frações com três a cinco gemas, de modo a facilitar a dissecação e excisão dos meristemas, e mantidos em placas de Petri em ambiente refrigerado. Os inóculos patógenos, nesse caso, ainda pemanecem intactos dentro da gema entre os folículos, mas não se movem para a região meristemática, à medida que cada folículo é destacado, o que permite a retirada estéril do meristema.

\section{Cultura de meristema}

Os meristemas dos diversos materiais foram assepticamente extraidos, em câmara de fluxo laminar sob lupa estereoscópica binocular, aumento $300 \mathrm{X}$ com o auxílio de pequenas pinças, bisturis e estiletes. Para cada folículo destacado da gema, o instrumento era imerso em álcool e flambado por duas vezes. Os meristemas com um a dois pares de primórdios foliares eram colocados em meio estéril de placa, por sete dias. Esse meio, distribuído em placas de Petri, foi composto dos macro e micronutrientes de MURASHIGE \& SKOOG (1962), ágar 0,6\%, sacarose $3 \%$ e carvão ativado $0,5 \%$, este último, para evitar o processo de oxidação do explante (Figura 1-A).

Após uma semana, os meristemas sem contaminação visível e não apresentando oxidação, eram colocados no meio para crescimento e proliferação, constituído dos macro e micronutrientes de MURASHIGE \& SKOOG (1962), com as seguintes adiçōes: sacarose $30 \mathrm{~g} / \mathrm{litro}$, ágar $6,5 \mathrm{~g} / \mathrm{litro}$, tiamina $1,0 \mathrm{~g} / \mathrm{litro}$, ácido nicotínico 0,25mg/litro, inositol $100 \mathrm{mg} / \mathrm{litro}$ e 6-benzilaminopurina (BAP), nas concentrações de $0,2,5,5,0,7,5$ e $15,0 \mu \mathrm{M}$ O pH foi ajustado a 6,0 , com uma solução a $0,1 \mathrm{~N}$ de $\mathrm{KOH}$. Foram utilizados para a cultura $10 \mathrm{ml}$ de meio em frascos de vidro de $53 \mathrm{ml}$ e vedados com filme plástico resinite.

Foram utilizados 25 meristemas para cada material e concentração de BAP, e incubados a uma temperatura de $28 \pm 2^{\circ} \mathrm{C}$, com fotoperíodo de 14 horas-dia, sob combinação de luz branca-fluorescente e incandescente, na proporção de 21 respectivamente. As reculturas foram realizadas mensalmente por cinco meses. Após esse periodo, avaliou-se o crescimento e a brotação dos materiais, obtendo-se a porcentagem de explantes que se desenvolveram em seus respectivos meios de cultura.

\section{Indução de raiz}

Os propágulos dos explantes com três pares de folhas, medindo cerca de 2 a $4 \mathrm{~cm}$ de altura, foram separados individualmente do feixe de brotação e transferidos, três por frasco de cultura, para o meio nutritivo para indução de raiz. Esse meio foi composto das mesmas concentrações de macro e micronutrientes, sacarose, ágar, tiamina, ácido nicotínico e inositol da fase anterior, substituindo-se apenas a citocinina BAP, pelo ácido indolbutírico nas concentrações de $0,1,0 ; 2,0$; 4,0 e $8,0 \mu \mathrm{M}$ 


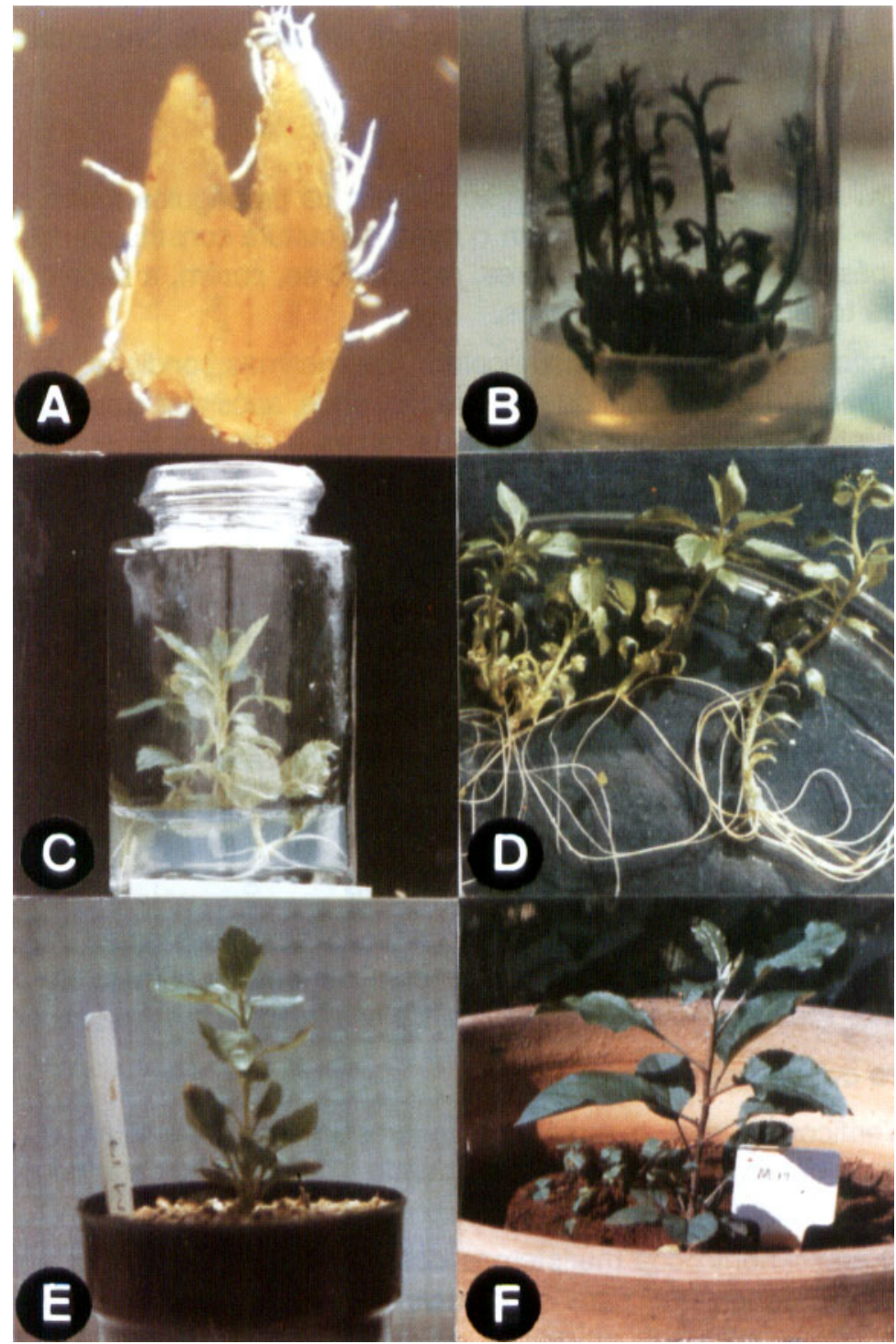

FIGURA 1. Propagação vegetativa in vitro de cultivares de macieira. Fase de proliferação: $\mathrm{A}=$ 'Rainha' - aumento 800x; B = IAC 4881-11 - 5,0 $\mu \mathrm{M}$ de BAP. Fase de enraizamento: $\mathrm{C}=$ 'Rainha' - 2,0 $\mathrm{MM}$ de $\mathrm{AIB} ; \mathrm{D}=$ 'Gala' - 2,0 $\mathrm{m} \mathrm{M}$ de AIB. Fase de aclimatização: $E=$ 'Rainha' e $F=$ 'Gala'. 
Trinta propágulos de cada material e concentração de AIB foram mantidos a $25 \pm 2^{\circ} \mathrm{C}$ de temperatura, no escuro, durante cinco dias. Adotou-se esse período em vista do melhor resultado alcançado em um teste preliminar, feito de cinco, dez e vinte dias.

\section{Enraizamento e crescimento apical}

Em seguida à fase de indução de raiz, os propágulos foram colocados em frascos - três em cada um - com o meio de cultura constituído dos mesmos nutrientes básicos das fases anteriores, reduzindo-se, porém, a sacarose a $1 \% \mathrm{e}$ excluindo-se totalmente os fitomônios.

Todos os materiais permaneceram nas mesmas condições de temperatura e de luminosidade da fase de proliferação, onde, após dez dias, fez-se a avaliação do efetivo enraizamento, número de raizes e do crescimento apical das plantas in vitro.

\subsection{Aclimatização e estabelecimento de plantas}

As pequenas plantas foram transferidas das condiçōes controladas de cultura para aclimatização (BRAINERD \& FUCHIGAMI, 1981) $\left({ }^{6}\right)$, em substrato de vermiculita umedecida com solução salina (MS - $25 \%$ ) e colocadas em uma miniestufa a $24 \pm 2^{\circ} \mathrm{C}$ de temperatura por cerca de quinze dias. Após esse período, as plantas já aclimatizadas foram transplantadas em vasos com terra e mantidas nas condições de casa de vegetação para o seu normal desenvolvimento.

\section{RESULTADOS}

Os dados de crescimento e de brotação dos meristemas, nas diversas concentrações de BAP, bem como os de enraizamento e número de raizes por propágulo nos meios de AIB, são apresentados nos quadros 1 e 2 respectivamente.

\subsection{Cultura de meristema}

Verificou-se que o regulador de crescimento 6-benzilaminopurina foi extremamente eficaz na indução do crescimento e da brotação para todos os materiais estudados (Quadro 1).

0 crescimento dos meristemas dos cvs. Gala e Rainha foi eficiente na faixa de $7,5 \mu \mathrm{M}$, sendo que para os demais materiais, 5,0 a $7,5 \mu \mathrm{M}$. mostrou-se mais apropriado: nestas concentraçōes, as seleçōes IAC 1381-22, IAC 3881-8 e IAC 4881-11 cresceram rapidamente, observando-se cerca de 15 pequenas brotações adventícias na parte basal de cada explante (Figura 1-B).

(6) Segundo BRAINERD \& FUCHIGAMI, 1981, o termo accilmatization, na língua inglesa, refere-se ao processo de adaptação de um organismo regulado pela intervençäo do homem, e acclimation, ao processo regulado pela natureza. Na língua portuguesa, os termos: aclimatização, aclimataçăo, aclimamento e aclimaçāo são sinônimos. 


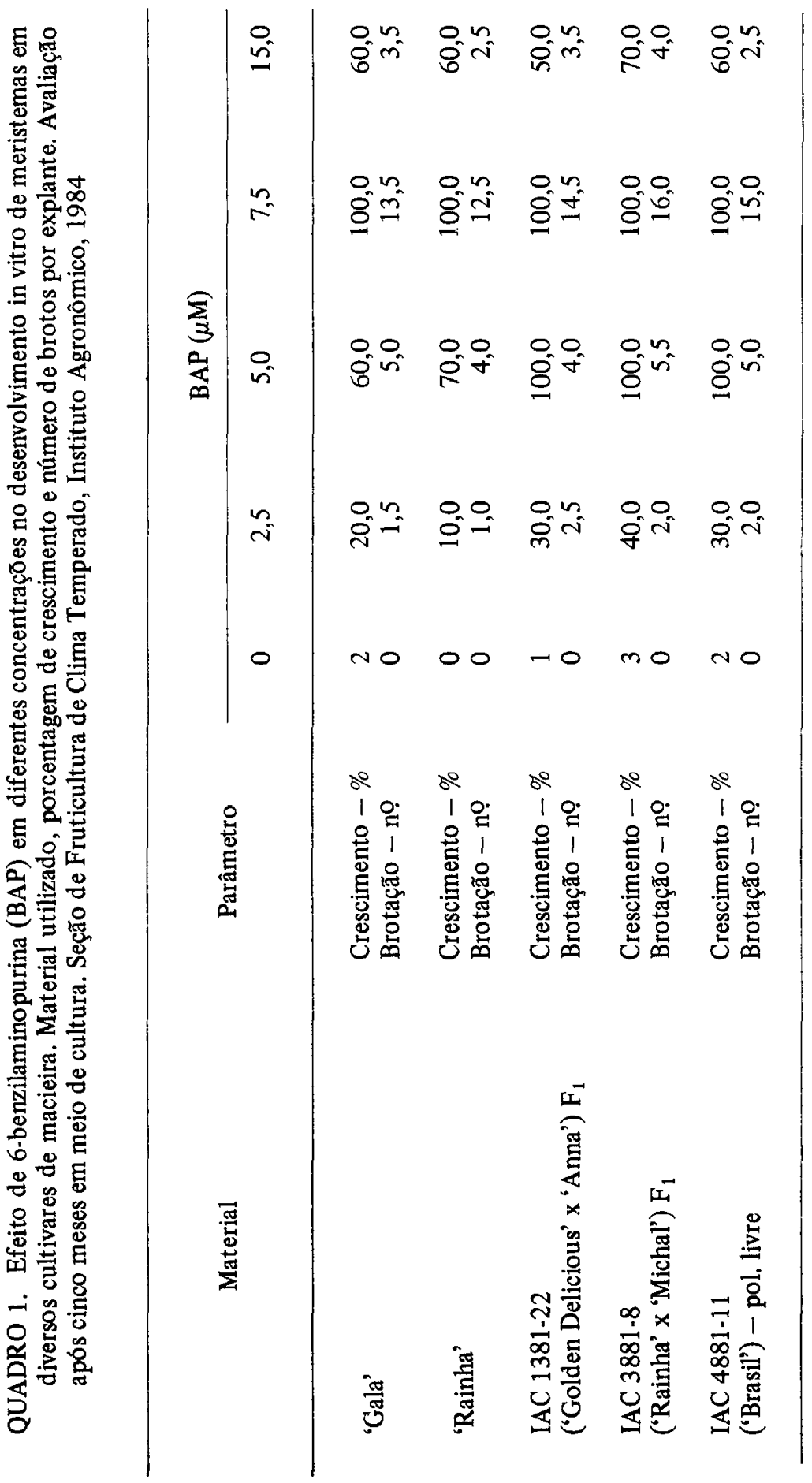


'Gala' e 'Rainha' apresentaram 12,5 a 13,5 brotações por explante, e crescimento mais lento que os demais. Os explantes que se desenvolveram nas concentraçōes de BAP de 2,5 e 15,0 $\mathrm{M}$ apresentaram baixo vigor vegetativo, com folhas pequenas e malformadas. $\mathrm{Na}$ concentração de $15,0 \% \mathrm{M}$, verificou-se ainda um desordenado crescimento de calo, prejudicando todo o crescimento do explante.

\subsection{Enraizamento e desenvolvimento apical}

O ácido indolbutíico, por sua vez, mostrou-se bastante eficaz no enraizamento da macieira, sobretudo na faixa de $2,0 \mu \mathrm{M}$ de $\mathrm{AIB}$, onde também apresentou maior número de raízes por propágulo.

Verificou-se que o período de cinco dias na indução de raízes com AIB, em ambiente escuro, foi suficiente para o bom enraizamento dos materiais utilizados, não havendo problemas da formação excessiva de calo. Com relação ao período de indução de raízes, os resultados confirmam aqueles obtidos por WELANDER (1983), no enraizamento in vitro do cv. porta-enxerto M 26.

Em todos os materiais, as primeiras raízes apareceram após o terceiro dia no meio sem hormônio e na luz, principalmente na faixa de 1,0 a $4,0 \mu \mathrm{M}$ do meio AlB indutor. Ao atingir o décimo dia no mesmo meio, verificou-se um alto índice de enraizamento na faixa de 2,0 $\mathrm{M}$. do meio AIB indutor para os cultivares Gala e Rainha, variando em média de 8,2 a 9,5 raizes por propágulo respectivamente (Quadro 2).

Para as seleções IAC 1381-22, IAC 3881-8 e IAC 4881-11, houve um excelente enraizamento na faixa de 1,0 a $4,0 \mu \mathrm{M}$, com leve tendência de acréscimo do número de raízes na faixa de $2,0 \mu \mathrm{M}$, na qual apresentaram a média de 10,4 a 11,6 raízes por propágulo. Nessa faixa, as raizes tiveram em vinte dias excelente crescimento, chegando a medir cerca de 8,0 a $12,0 \mathrm{~cm}$ de comprimento, dependendo do material (Figura 1-C e D).

Nesta fase de enraizamento, os propágulos deixaram de brotar lateralmente na base e desenvolveram-se predominantemente na parte apical. Em dez dias no meio sem hormônio e nạ luz, os propágulos alongaram-se aproximadamente $2 \mathrm{~cm}$, já apresentando aspecto de uma pequena planta bem formada, com caule vigoroso, internódios mais curtos e folhas verde-escuras largas.

Nas concentraçóes superiores a $4,0 \mu \mathrm{M}$, as poucas ralzes observadas eram bem vigorosas, porém nāo chegaram a se desenvolver como nas concentrações inferiores. Os propágulos remanescentes, sem raizes, no mesmo meio definharam, chegando à morte após um curto período. 
列

통ㅇㅇㅇ

$\stackrel{800}{0.00}$

등ㅇㅇ

능

古宫

o 5

N

언

58

$\Xi$ 을 울

०

政

㞼。

政

잉

욜요

的

응

춘

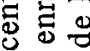

\%

E

空

苛.

边

무의

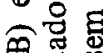

宽

学

要

要

웡

要

응

해

옹

过

密等:

(i)

त

웅

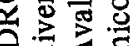

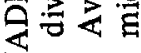

8

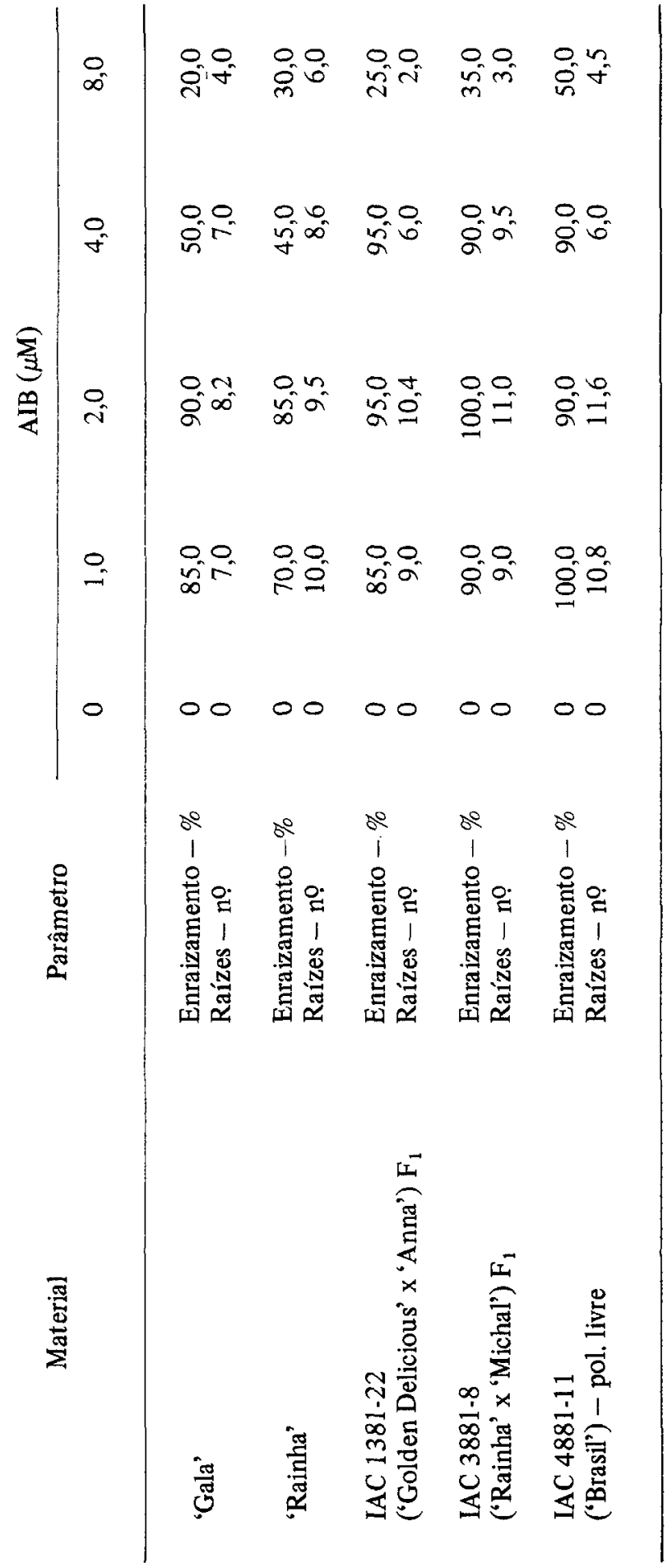

Bragantia, Campinas, 45(1):143-154, 1986 


\subsection{Aclimatização e estabelecimento das plantas}

Decorridos dez dias em meio de enraizamento, os propágulos já estavam aptos a ser aclimatizados no ambiente natural. Esta fase de aclimatizaçăo torna-se imprescindivel devido ao contraste da umidade relativa dentro e fora do frasco de crescimento controlado. O período de quinze dias de permanência das plantas em miniestufa foi suficiente para uma aclimatização adequada, tornando-as aptas a passar do frasco de cultura com $100 \%$ de umidade para condiçōes variáveis de umidade relativa do ambiente natural (Figura 1-E e F).

As plantas estabelecidas em terra e mantidas em casa de vegetação apresentaram após o segundo mês um crescimento normal, chegando a medir cerca de 10 a $20 \mathrm{~cm}$ de altura na maioria dos materiais (Figura 1-F).

\section{DISCUSSÃO}

A propagação vegetativa in vitro da macieira, pela possibilidade de produzir plantas idênticas e sadias, com economia de espaço e de tempo, poderá estimular as organizações viveiristas mais tecnificadas a adotar a metodologia nas condições brasileiras.

Utilizando-se as concentrações ideais dos fitormônios para crescimento, brotação e enraizamento, estima-se que, partindo de apenas 100 explantes, mais de 500.000 plantas transplantadas em terra poderiam ser produzidas em $18 \mathrm{me}-$ ses ou menos.

Convém lembrar, no entanto, que para um adequado emprego comercial de propágulos da macieira, multiplicados in vitro, torna-se necessário o estudo preliminar detalhado de combinações hormonais requeridas pelo cultivar em questāo. O mesmo material poderá exigir diferentes concentrações de cada hormônio ou de determinado reguiador de crescimento, dependendo inclusive da fase de desenvolvimento da planta matriz (WELANDER, 1983).

Finalmente, maiores estudos são ainda imprescindíveis, a fim de avaliar o comportamento no campo, a exemplo do porte, produtividade e longevidade útil das macieiras microvegetativamente propagadas e desenvolvidas sobre suas próprias raizes, sem a utilização de porta-enxertos.

\section{SUMMARY}

IN VITRO PROPAGATION OF APPLE CULTIVARS IN BRAZIL

Experiments on apple micropropagation were carried out in the laboratories of the Instituto Agronômico, Campinas, Brazil. The main hormonal requirements of shoots in the different development phases - 
growing, proliferation, root induction and effective root and shoot development - were studied in five apple cultivars: Rainha, Gala and the selections IAC 1381-22, IAC 3881-8 and IAC 4881-11. The best technique for apple micropropagation in our conditions was found to consist of: a) growth of meristems in Murashige and Skoog saline solution culture medium supplemented with $1.0 \mathrm{mg} /$ liter thiamin $\mathrm{HCl}, 0.25 \mathrm{mg} /$ liter nicotinic acid, $100 \mathrm{mg} /$ liter myo-inositol, $6.5 \mathrm{~g} /$ liter agar, $30 \mathrm{~g} / \mathrm{liter}$ sucrose and $7.5 \mu \mathrm{M}$ BAP (6-benzylàminopurine); b) transfer to dark room for 5 days in a root induction medium containing the same mineral and organic constituents of the first solution, only changing BAP for $2.0 \mu \mathrm{M}$ IBA (indole-3-butiric acid); and c) transfer to a root growth medium basically equal to the other except that no phytohormones was added. The rooted plantlets were potted in vermiculite, watered with a dilute mineral solution and kept in a growth chamber under high moisture for 15 days; finally they were potted in a soil mixture and transferred to a greenhouse.

Index terms: apple, Malus spp., meristem culture, in vitro rooting, explant, shoots, BAP, IBA.

\section{AGRADECIMENTO}

Os autores agradecem a Meire C. Silva Ferrari, Técnica de Laboratório da Seção de Viticultura do IAC, a prestimosa colaboração ao desenvolvimento deste trabalho.

\section{REFERÊNCIAS BIBLIOGRÁFICAS}

ABBOT, A.J. \& WHITELEY, E. Culture of Malus tissues in vitro I. Multiplication of apple plants from isolated shoot apices. Scientia Horticulturae, 4:183-189, 1976.

BARBOSA, W.; CAMPO DALL'ORTO, F.A. \& OJIMA, M. Aspectos reprodutivos das fruteiras de clima temperado, objetivando o melhoramento genético. O Agronômico, Campinas, 35:15-20, 1983.

BRAINERD, K.E. \& FUCHIGAMI, L.H. Acclimatization of aseptically cultural apple plants to low relative humidity. Journal of the American Society for Horticultural Science, 106:515-518, 1981.

CAMPO DALL'ORTO, F.A.; OJIMA, M.; RIGITANO, O.; SCARANARI, H.J. \& MARTINS, F.P. Germinação de sementes de maçã. Bragantia, Campinas, 37:83-91, 1978.

EMPRESA BRASILEIRA DE ASSISTÊNCIA TÉCNICA E EXTENSÃO RURAL/EMPRESA BRASILEIRA DE PESQUISA AGROPECUÁRIA. Sistemas de produção para maçã. Florianópolis, EMPASC/ACARESC, 1984. 100p. (EMBRAPA Sistema de Produção, boletim, 380)

JAMES, D.J. \& THURBON, I.J. Shoot and root iniciation in vitro in the apple roostock M.9 and promotive effects of phloroglucinol. Journal of Horticultural Science, 56:15-20, 1981.

JONES, O.P. \& HATFIELD, S.G.C. Root initiation in apple shoots cultured in vitro with auxins and phenolic compounds. Journal of Horticultural Science, 5:495-499, 1976. 
LANE, D.W. \& McDOUGALD, J.M. Shoot tissue culture of apple; comparative response of five cultivars to cytokinin and auxin. Canadian Journal of Plant Science, 62:689-694, 1982.

MURASHIGE, T. \& SKOOG, F. A revised medium for rapid growth and bioassays with tobacco tissue cultures. Physiologia Plantarum, 15:473-497, 1962.

RIBEIRO, P.A.; CAMILO, A.P.; PETRI, J.L.; PEREIRA, A.J. \& CAMALATO, D. Comportamento de algumas cultivares de macieira em Santa Catarina. Florianópolis, EMPASC, 1982. 15p. (Boletim técnico, Série Fruteiras, 5)

RIGITANO, O.; OJIMA, M. \& CAMPO DALL'ORTO, F.A. Novos cultivares de maçã para o clima paulista. 2.ed. Campinas, Instituto Agronômico, 1984. 11p. (Boletim Técnico, 31)

SIMMONDS, J. Direct rooting of micropropagated M 26 apple rooststocks. Scientia Horticulturae, 21:233-241, 1983.

VAZ, R.L. \& NEGUEROLES, J. Micropropagação e influência do tempo de permanência em meio contendo floroglucinol no enraizamento de brotos apicais de pessegueiro e macieira. Goiânia, EMGOPA, 1979. 5p. (Comunicado Técnico, 17)

WELANDER, M. In vitro rooting of the apple rootstocks $M 26$ in adult and juvenile growth phases and acclimatization of the plantlets. Physiologia Plantarum, 58:231-238, 1983.

ZIMMERMAN, R.H. \& BROOME, O.C. Phloroglucinol and in vitro rooting of apple cultivar cuttings. Journal of the American Society for Horticultural Science, 106:648-652, 1981. 